\section{British National Formulary}

Sir: Drs Srinivasan and Birch (Psychiatric Bulletin. January 1994, 18, 52) have commented adversely on the British National Formulary (BNF). I would be grateful for the opportunity to set the record straight.

With reference to the dose of Depixol injection, doses in the BNF reflect the data sheet doses, which are the doses that have the confidence of the UK Licensing Authority. Thus, the dose of Depixol injection in the BNF reflects the dose in the 1993-94 ABPI Data Sheet Compendium.

With reference to the legal status of the BNF, it has the role of a pocket book, primarily for general practice, aimed at encouraging rational and cost-effective prescribing. The BNF is produced under the authority of a Joint Formulary Committee which includes representatives from the British Medical Association, the Royal Pharmaceutical Society and the Department of Health. Although individual drug monographs in the BNF reflect the data sheet requirements, the preamble to the drug monographs reflects the independent view of the Joint Formulary Committee. In providing its guidelines the Joint Formulary Committee uses advisers who are practising expert clinicians in the different specialties covered.

With reference to the Royal College Consensus Group, I attended the December 1993 meeting as an observer and explained the BNF policy to the meeting. The Joint Formulary Committee has always resisted requests to include doses of antipsychotics higher than those licensed, but for many editions has acknowledged that in some patients it is necessary to raise the dose above that which is normally recommended (with the proviso that this should be done with caution and under specialist supervision). The consensus group has thus used the BNF doses as a convenient shorthand for the licensed doses. Furthermore for BNF No 28 our brief statement on high-dose antipsychotic therapy will be expanded, by mutual agreement, to incorporate the conclusions of the Consensus Group.

Therefore, rather than being critical, I believe, the Consensus Group has welcomed the cooperation of the BNF.

With reference to lithium, the BNF is already in accord with the clinical guidelines produced by the Working Party of the Third British Lithium Congress.
ANNE B. PRASAD, Executive Editor, British National Formulary, Royal Pharmaceutical Soclety of Great Brttain, 1 Lambeth High Street, London SEI 7JN

\section{Neuroleptic usage}

Sir: I read with interest D. Gill's letter regarding antipsychotic use in relation to dose, route and polypharmacy (Psychiatric Bulletin, 1993, 17, 773-774). In 1992 I performed an audit of neuroleptic usage in acute patients at Central Hospital, Warwick in which additional p.r.n. prescribing indicated possible exceeding of BNF dose guidelines.

The total number of patients was 47 of whom $32(68 \%)$ were on a neuroleptic (either regular or p.r.n.). Seventeen were on one regular neuroleptic, ten were on more than one and one was on three regular neuroleptics. Nine patients (or $28 \%$ of those on neuroleptics) were receiving antiparkinsonian medication of whom five were prescribed more than one neuroleptic. Fourteen patients were prescribed p.r.n. neuroleptics, five also taking one or two regular neuroleptics. Only three patients had not received any p.r.n. medication. For patients on more than one neuroleptic, where one was a p.r.n., most were written up by the duty doctor.

Despite careful prescribing habits of teams it seems that patients still run the risk of exceeding BNF doses and experiencing side effects when p.r.n. prescriptions are taken into account. Supplementary neuroleptic prescribing for acutely disturbed patients by duty doctors is common. Perhaps a time limit on all p.r.n. medication would avoid such unseen errors occurring.

SUSAN CARVILL, Heathlands (Charles Burns Clinic) Btrmingham B13 8QD

\section{Relatives and schizophrenia}

Sir: In the study by Brian O'Shea (Psychiatric Bulletin, January 1994, 18, 32-35) voluntary schizophrenia organisations were contacted for information, including enquiry into the helpfulness of the medical profession. I was surprised that no reply was received from the National Schizophrenia Fellowship in the UK. In my own study I interviewed relatives who were members of a branch of the NSF/UK and asked their views 